\title{
CREEP OF SMALL DIAMETER TIMBER POLES
}

\author{
M T P Hettiarachchi \\ Department Of Civil Engineering \\ University of Moratuwa \\ Moratuwa
}

It has become necessary to encourage the use of small diameter timber poles (plantation thinnings) as building timber particularly in roof construction, as the supply of better known indigenous species can no longer meet the increasing demand for construction timber. Eucalyptus and Pinus species were introduced to Sri Lanka some years ago and at present there exists a large area under their plantation. While the larger diameter trees are used in pole form for transmission poles or are processed for furniture, the thinnings have had little use. Preliminary studies were carried out to assess the feasibility of using the thinnings as roof timber. The mechanical properties were found to be adequate. Both these species however need to be preservative treated to increase their durability. Boron diffusion was considered a cost effective method of treatment provided the poles are used while still green. Previous studies have shown that the poles removed from a Boron preservative tank took 3 to 4 months to reach equilibrium moisture content. Thus they must be allowed to dry out under load.

The limiting of deflection often controls the design of seasoned timber beams. It is thus expected that limiting deflection, will be more the controlling design requirement for the green poles drying out under load. The magnitude of long term or creep deflection that occurs as the poles dry out under load is thus significant and needs to be determined.

This paper describes an investigation into the creep behaviour of initially green small diameter timber poles drying out under load. The magnitude of a factor that can be applied to instantaneous elastic deformation to evaluate long term deformation is determined experimentally for timber poles of Eucalyptus and Pinus species of different diameters drying out under a range of bending stresses.

Proceedings of the Third Annual Forestry Symposium 1997, of the Department of Forestry and Environmental Science, University of Sri Jayewardenepura, Sri Lanka 